\title{
Transient STEMI with Spontaneous Resolution as an Infrequent Intraoperative Complication of Radiofrequency Ablation of Symptomatic Premature Ventricular Contractions
}

\author{
Roberto Cerrud Rodriguez*, Daniel Rodriguez, Diego Alcaraz Alvarez, Roman Castillo, Opeyemi Ayeni and \\ Salim Baghdadi
}

Department of Internal Medicine, SBH Health System, USA

Submission: January 22, 2019; Published: February 08, 2019

*Corresponding author: Roberto Cerrud Rodriguez, Department of Internal Medicine, SBH Health System, 4422 3rd Avenue, Bronx, NY, 10457, USA.

\section{Introduction}

Radiofrequency ablation (RFA) is a treatment option for patients with ventricular arrhythmias (VA) when antiarrhythmic drugs are ineffective, not tolerated or not desired by the patient [1]. Among the complications associated with RFA of VA, STEMI is an uncommon complication with very few cases reported on the literature.

We report the case of a 68-year-old male who presented with a high-burden of symptomatic premature ventricular contractions (PVC) and lack of improvement with beta-blockers who underwent an EP study and RF ablation developing STEMI with spontaneous resolution. This case report intends to create awareness on this complication, instruct on the anatomic relationships to be taken into consideration when performing this procedure and the way to proceed when facing this scenario.

\section{Case Report}

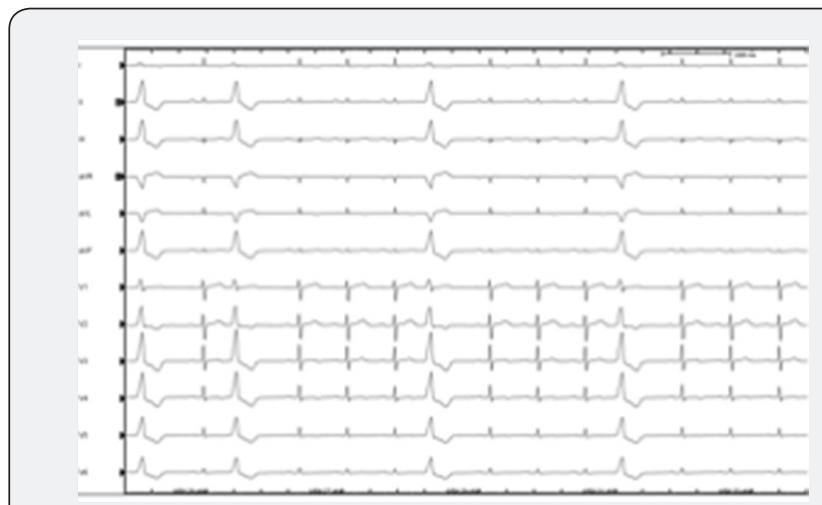

Figure 1: Baseline EKG.
A 68-year-old Filipino male was referred to the electrophysiology (EP) clinic due to recurrent episodes of palpitations onset several years before. An EKG showed frequent PVCs with right-bundle branch block (RBBB) morphology. Holter monitor reported a PVC burden of $25 \%$. A transthoracic echocardiogram (TTE) showed normal left-ventricular (LV) size, function, with ejection fraction $56 \%$. He was challenged with beta-blockers, which failed to improve his symptoms (Figure 1).

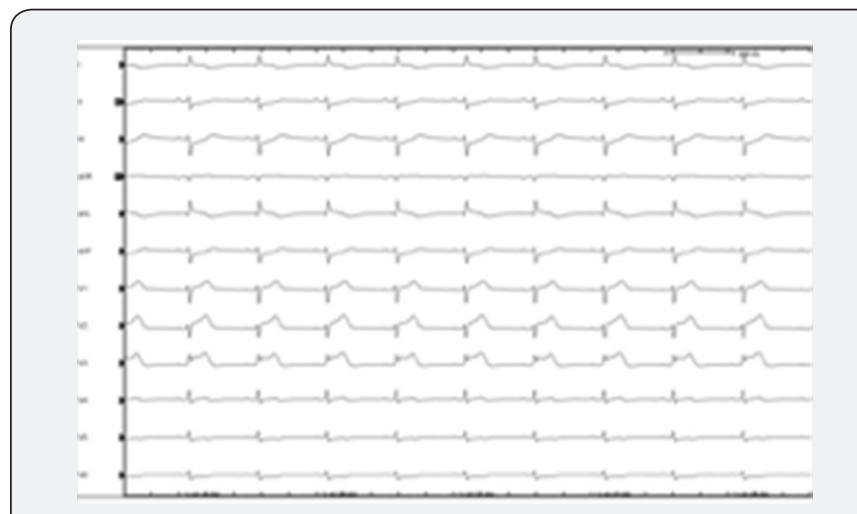

Figure 2: Stemi in the anteroseptal leads.

Therefore, it was decided to perform an EP study with possible ablation, given the risk of developing PVC-associated $\mathrm{LV}$ dysfunction. On presentation to the EP lab, the patient was in sinus rhythm with frequent monomorphic PVCs every 2 to 5 beats with episodes of bigeminy. Using the modified Seldinger technique with ultrasound guidance, fluoroscopic landmarks, and micropuncture technique, right femoral venous access was achieved (8 French). Right femoral artery access was obtained 
(4F). Left femoral venous access was also obtained (5F and 11F). A quadrapolar catheter was positioned in the right ventricular septum. An intracardiac echocardiography catheter was advanced and used to assist in generating geometry of the aortic valve cusps, identify the coronary artery ostia, and monitor for complications. The left main was identified. The $8 \mathrm{~F}$ was used to introduce an irrigated RFA catheter (Smart Touch D,F) (Figure 2).

The Biosense Webster CARTO3 3D electroanatomical mapping system was used. Force-time integral calculation, stability and impedance drops were used to assess lesion quality. A Deca Nav catheter was used for PVC mapping through the coronary sinus (CS). The earliest activation was in the distal CS near the anterior interventricular vein. The $4 \mathrm{~F}$ arterial sheath was exchanged for $8 \mathrm{~F}$ sheath and a heparin bolus and drip were started to achieve an activated coagulation time of approximately 300 seconds. The catheter was advanced to the aortic cusps/LV outflow tract (LVOT). Activation mapping of the aortic cusp of the aortic valve was done. LVOT activation was also mapped; however, the earliest activation was in the CS with $10 \mathrm{~ms}$ preQRS. The ablation catheter was then advanced into the CS and multiple RF lesions were delivered, which caused the suppression of PVC with early recurrence (Figure 3).

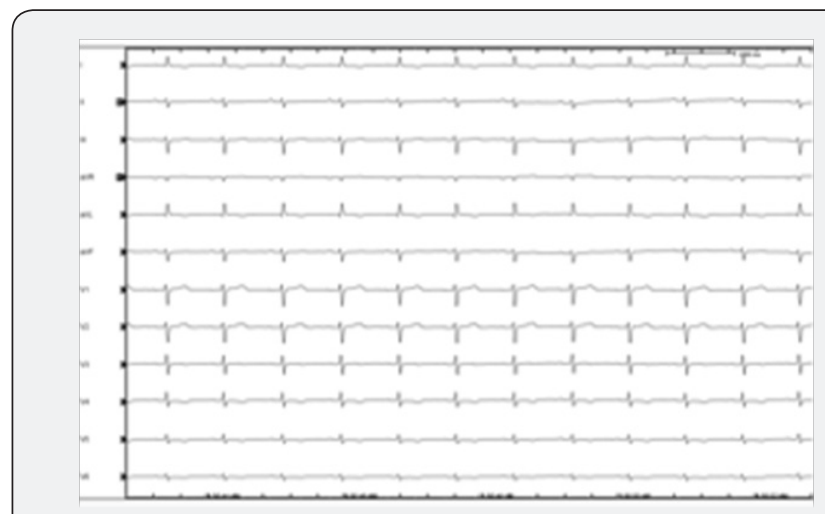

Figure 3: Stemi resolution.

The ablation catheter was advanced again retrograde through the aorta and activation was found in the LV at the aortomitral continuity area. There was a fractionated signal pre-QRS and earliest activation was $22 \mathrm{~ms}$ pre-QRS. Unipolar signal showed QS pattern. RF lesions were given that led to immediate suppression of PVCs. Immediately after the lesions were delivered, the patient complained of oppressive chest pain. A STEMI was found in V1V4, associated with brief hypotension and troponin release. A stat TTE showed LV hypokinesis. The STEMI resolved without intervention after approximately 5 minutes, with recovery of normal LV wall motion. A coronary angiogram was done during the same procedure and showed stable 2-vessel coronary artery disease: proximal left-anterior descending (LAD) discrete stenosis $60 \%$ and $70 \%$ stenosis of distal right posterolateral branch of the right coronary artery (RCA). No acute thrombus was seen. Given these findings, we suspect that the STEMI was caused by coronary vasospasm on top of the stable CAD (Figure 4).



Figure 4: Post RF Ablation EKG.

\section{Discussion}

Approximately two thirds ofidiopathic ventriculararrhythmias originate from the ventricular outflow tracts; $20 \%$ having its origin in the left tract. There is an area of fibrocartilaginous density located at the ventricular mass, which provides electrical insulation at the atrioventricular level and fibrous continuity for the leaflets of the aortic, mitral and tricuspid valves. These fibrous areas are composed by aortic-mitral continuity, the fibrous trigones, the membranous septum, the interleaflet triangles, the subvalvar collar of the mural leaflet of the mitral valve, the conus ligament and the tendon of Todaro. The aortic valve consists of 3 leaflets (right, left and non-coronary leaflets) with deep closure lines buttressed by the nodule of Arantius. The configuration of the leaflets crosses the ventricular-arterial junction, the continuity between the anterior leaflet of the mitral valve (called the aortic leaflet) and the noncoronary and right coronary leaflets of aortic valve creates a fibrous continuation between the mitral and aortic valve [2]. Laterally the fibrous tissue is thickened and forms the right and left fibrous trigones. Extending from the left fibrous trigone at the posterior left coronary leaflet to the right fibrous trigone between the right and non-coronary leaflets is the aortomitral continuity area, which separates the left ventricular inflow and outflow tracts. The aorto-mitral continuity area is composed of a middle, right and left segments. Extending from the right to the left fibrous trigone, is the being the middle segment, providing fibrous continuity with the aortic valve. Extending from the mitral commissure and a fibrous trigone and attached to the margins of the roof of the $\mathrm{LV}$, respectively are the right or superior and left or inferior segment of the anterior annulus. This area is continuous with the interleaflet triangle between the left and nonfacing sinuses of the aorta, with this area forming the posterior wall of the LV outflow tract (LVOT). As there is no myocardium between the aortic and mitral valves (fibrous trigone), VA originating in the LV usually originate from along the LV ostium. Although this is a fibrous structure, AV node-like cells have been identified in this area [3]. RFA successfully eradicates the arrhythmia, but do to its close proximity to the coronaries, the procedure can result in fatal outcomes $[4,5]$. 
The existing relationship between the accessory pathways and the CS can lead to uncommon complications such as STEMI. A few reports have been published, involving the territories involving the posterolateral (inferolateral) branch (PLA) of the RCA [6]. Among the multiple potential causes of STEMI during RFA, coronary vasospasm has been the most commonly implicated mechanism, followed by thermal lesion and coronary dissection due to catheter manipulation [7]. The incidence of STEMI as a complication of ablation of VA has been reported to be $<0.2 \%$ by Calkins et al., who reported a case series of 106 patients undergoing RFA, where there was a single case of a STEMI caused by thrombotic occlusion of left main coronary artery, requiring angioplasty of the culprit lesion. The authors believe the STEMI was precipitated by direct positioning of the catheter over the left main coronary artery [8]. Simon et al. reported a series of 3 cases of STEMI following RFA, where all cases resolved after administration of intracoronary nitrates with no angiographic evidence of obstruction [9]. In our patient, we strongly believe the STEMI was caused by coronary vasospasm, evidenced by its spontaneous resolution and lack of angiographic evidence of intracoronary thrombus, as well as the almost immediate recovery of LV function after the event resolved.

\section{Conclusion}

Our case describes a very unusual complication of a common procedure. Although in our patient the STEMI resolved spontaneously, we recommend immediate coronary angiography to determine the etiology and to treat accordingly. Intracoronary nitrates can be given in cases where the coronary vasospasm is evidenced during angiography.

\section{Teaching Points}

ST elevation is an uncommon complication of RFA.

A common cause of STEMI during RF ablation is coronary spasm, for which intracoronary nitrates might be required in some cases

\section{References}

1. Al Khatib SM, Stevenson WG, Ackerman MJ (2018) 2017 AHA/ACC/HRS Guideline for Management of Patients with Ventricular Arrhythmias and the Prevention of Sudden Cardiac Death. J Am Coll Cardiol: 72.

2. Hai JJ, Lachman N, Syed FF, Desimone CV, Asirvatham SJ (2014) The anatomic basis for ventricular arrhythmia in the normal heart: what the student of anatomy needs to know. Clin Anat 27(6): 885-893.

3. Szili Torok T, van Malderen S, De Groot N (2012) 'Born' with a 'dead'end-tract resulting in arrhythmias in the aorto-mitral continuity: coincidence, causation, and 'commensuration'. Europace14 (3): 308309.

4. Kumagai K, Fukuda K, Wakayama Y (2008) Electrocardiographic characteristics of the variants of idiopathic left ventricular outflow tract ventricular tachyarrhythmias. J Cardiovasc Electrophysiol 19: 495-501.

5. Al Khatib SM, Stevenson WG, Ackerman MJ (2018) 2017 AHA/ ACC/HRS guideline for management of patients with ventricular arrhythmias and the prevention of sudden cardiac death: Executive summary: A Report of the American College of Cardiology/American Heart Association Task Force on Clinical Practice Guidelines and the Heart Rhythm Society. Heart Rhythm 15: e190-e252.

6. Mao J, Moriarty JM, Mandapati R, Boyle NG, Shivkumar K, Vaseghi M (2015) Catheter ablation of accessory pathways near the coronary sinus: Value of defining coronary arterial anatomy. Heart Rhythm 12(3): 508-514.

7. Yalin K, Golcuk E, Bilge AK, Umman S, Adalet K (2012) Successful stenting of a left main coronary artery occlusion as a complication of RF ablation for Wolff-Parkinson-White syndrome. Pacing Clin Electrophysiol 35: e43-e46.

8. Calkins H, Sousa J, el Atassi R (1991) Diagnosis and cure of the Wolff-Parkinson-White syndrome or paroxysmal supraventricular tachycardias during a single electrophysiologic test. N Engl J Med 324 (23): 1612-1618.

9. Simon RD, Gill JS (2003) Coronary ischemia induced by radiofrequency ablation in the left atrium. J Cardiovasc Electrophysiol 14(2): 186-190.

\begin{tabular}{l} 
Your next submission with Juniper Publishers \\
will reach you the below assets \\
- Quality Editorial service \\
- Swift Peer Review \\
- Reprints availability \\
- E-prints Service \\
- Manuscript Podcast for convenient understanding \\
- Global attainment for your research \\
- Manuscript accessibility in different formats \\
( Pdf, E-pub, Full Text, Audio) \\
- Unceasing customer service \\
Track the below URL for one-step submission \\
https://juniperpublishers.com/online-submission.php \\
\hline
\end{tabular}

